\title{
Management of paediatric tuberculosis in provincial and district hospitals in Afghanistan
}

\author{
F.M. Delawer, ${ }^{7}$ M. Isono, ${ }^{2}$ H. Ueki, ${ }^{2}$ M. Zhuben, ${ }^{1}$ M. Zafari, ${ }^{7}$ M.K. Seddiq, ${ }^{7}$ H. Habib ${ }^{7}$ and M.K. Ayoubi ${ }^{1}$
}

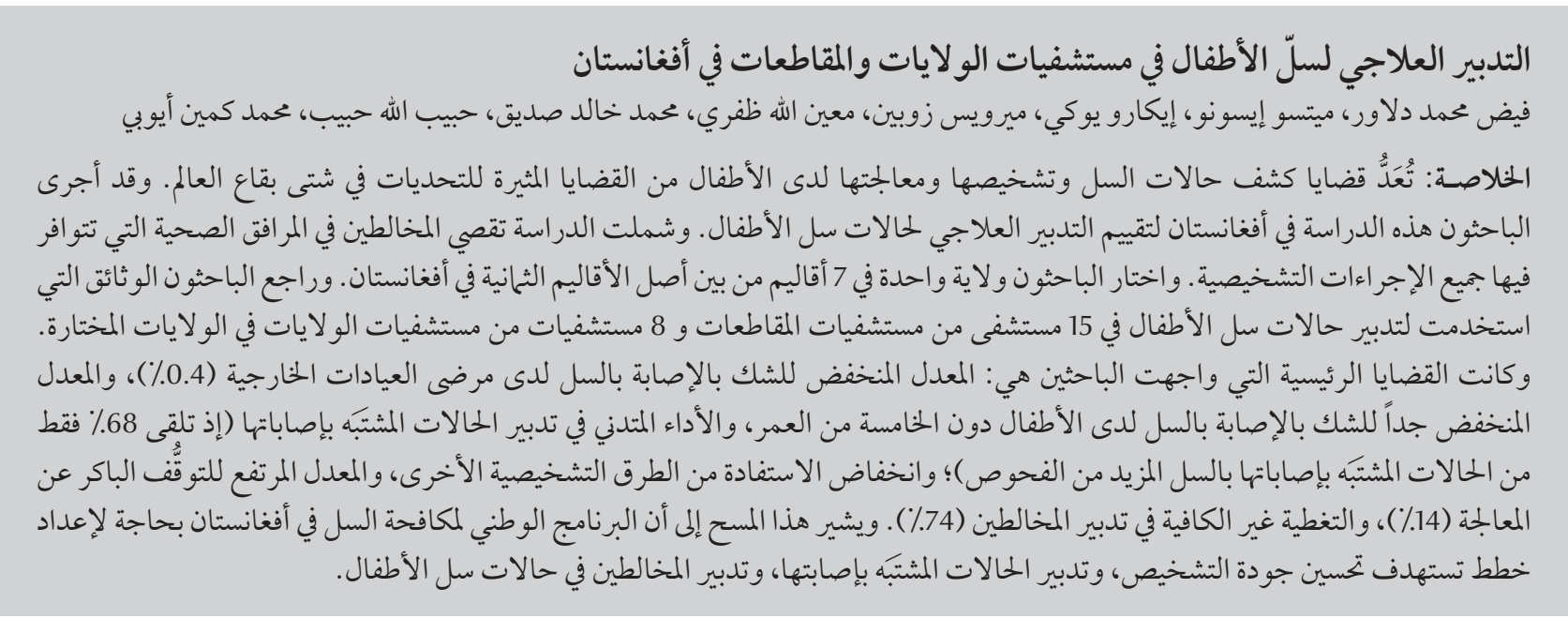

ABSTRACT Case detection, diagnosis and treatment of tuberculosis (TB) in children are challenging issues worldwide. This study in Afghanistan aimed to evaluate paediatric TB case management, including contact investigation, at health facilities where all diagnostic processes were available. In 7 out of 8 regions of the country 1 province was selected. Documents used for management of paediatric TB cases were reviewed in 15 distinct hospitals and 8 provincial hospitals in the selected provinces. The key issues which emerged were: a low suspect rate among total outpatients $(0.4 \%)$ and a very low suspect rate among children aged $<5$ years; low performance of suspect management (68.5\% suspects received further examinations); low utilization of other diagnostic methods; a high early defaulter rate (14.0\%); and insufficient coverage of contact management $(74.0 \%)$. This survey indicated that the Afghanistan national TB programme needs to develop plans to improve the quality of diagnosis, suspect management and contact management in paediatric TB cases.

\section{Prise en charge de la tuberculose chez l'enfant dans des hôpitaux de province et de district en Afghanistan}

RÉSUMÉ Le dépistage, le diagnostic et le traitement de la tuberculose chez l'enfant constituent des défis dans le monde entier. La présente étude menée en Afghanistan visait à évaluer la prise en charge des cas de tuberculose chez l'enfant, notamment la recherche des cas-contacts, dans les établissements de soins où toutes les méthodes de diagnostic étaient disponibles. Une province a été choisie dans sept régions du pays sur huit. Les documents utilisés pour la prise en charge des cas de tuberculose chez l'enfant ont été passés en revue dans 15 hôpitaux de district et 8 hôpitaux provinciaux dans les provinces sélectionnées. Les principaux problèmes qui ont été dégagés sont les suivants : un faible pourcentage de cas suspects $(0,4 \%)$ chez tous les patients en consultation externe et un très faible pourcentage de cas suspects chez les enfants de moins de cinq ans ; une mauvaise efficacité de la prise en charge des cas suspects ( $68,5 \%$ des cas suspects ont bénéficié d'examens complémentaires) ; un recours trop rare à d'autres méthodes diagnostiques ; un taux d'abandon précoce élevé (14\%); et une couverture insuffisante de la prise en charge des cas-contacts $(74,0 \%$ ). Cette enquête indique que le programme national de lutte contre la tuberculose en Afghanistan a besoin d'élaborer des plans visant à améliorer la qualité du diagnostic et de la prise en charge des cas suspects et des cas-contacts dans les cas de tuberculose chez l'enfant. 


\section{Introduction}

Case detection, diagnosis and treatment including chemoprophylaxis of tuberculosis (TB) among children are challenging issues. TB control in paediatrics is one of the target components of the Stop TB strategy [1]. It is also recommended by the World Health Organization (WHO) to screen all the contacts of TB patients especially children who have close contact with sputum-smear positive (SS+) pulmonary TB cases [2]. Despite the importance of $\mathrm{TB}$ control in children, it is often accorded low priority by national $\mathrm{TB}$ control programmes (NTP) because the disease is rarely in the contagious form and factors such as diagnostic difficulties, misplaced faith in bacille CalmetteGuérin (BCG) vaccination, countries' limited resources and lack of proper surveillance systems [3-7].

In Afghanistan TB control in children faces the same problems. Almost 2000 paediatric TB cases are estimated to occur annually in Afghanistan, but in fact in 2010 nearly 2700 paediatric pulmonary TB cases ( $<15$ years old) were reported. However, in nearly $60 \%$ of these cases sputum smear examinations were not done or were not available and the accuracy of diagnosis of those cases remained uncertain. To understand the exact situation of paediatric TB control and to develop a plan for proper identification and treatment of childhood TB is very important for a number of reasons. Although children contribute little to disease progression, children with $\mathrm{TB}$ differ from adults in their response to the disease in many ways, including a rapid progression of disease, which may have important implications for the prevention, diagnosis and treatment of TB. The incidence of TB in children reflects the status of TB control efforts in the adult population because children serve as indicators of contagious adolescents or adults with TB [6]. There is a high prevalence of women of reproductive age with TB in Afghanistan and this might cause a higher incidence of $\mathrm{TB}$ in childhood, especially in neonates and toddlers [8].

This study therefore aimed to determine the current status of management of paediatric TB control, including contact investigation, in provincial hospitals and district hospitals where TB diagnostic facilities for children are in place (X-ray and laboratory examinations) and a majority of childhood TB cases are referred from primary health care facilities.

\section{Methods}

This was an observational, retrospective study conducted from December 2010 to May 2011 to evaluate the paediatric TB case management at those health facilities where all diagnostic processing were available.

\section{Setting and sample}

From all 8 regions of the country, the south region was excluded due to security problems. For the other 7 regions, 1 province (Bamyan, Takhar, Nengarhar, Hirat, Badakhshan, Saripul and Paktea) was selected from each region. All 15 district hospitals and 8 provincial hospitals in the selected provinces were target sites of this survey.

All children aged $\leq 15$ years registered in the selected hospitals during the study period were enrolled in the study.

\section{Data collection}

The TB related documents used for registration and management of paediatric TB cases were reviewed and recorded in a predesigned data collection form. The reviewed documents were: general outpatient department register, TB suspect register, TB laboratory register, TB treatment register, contact register, treatment cards of $\mathrm{TB}$ patients and records of chemoprophylaxis for contacts aged $<5$ years. All the children registered in general outpatient departments
(OPD) and TB forms of the clinic aged $\leq 15$ years old were enrolled.

This study was reviewed and approved in advance by the institutional review board of the Afghan Public Health Institute.

\section{Case definitions}

Paediatric: children aged $0-15$ years old.

Sputum smear positive (SS+): a patient with 2 or more initial SS+ results or $1 \mathrm{SS}+$ result with radiographical abnormalities consistent with active pulmonary TB as determined by clinician or $1 \mathrm{SS}+$ result with culture.

Household contact: someone living in the same household with a SS+ pulmonary TB patient as a source case (e.g. the child's caregiver) or in frequent contact with a source case.

Provincial and district hospital: referral hospital where $\mathrm{X}$ - ray and microscopy services were available for diagnosis of $\mathrm{TB}$ with $\mathrm{TB}$ registration system.

\section{Results}

\section{Availability of guidelines}

The national TB guidelines were available in 22 out of the 23 hospitals reviewed, while the Afghan NTP guideline Standard Operational Procedure for Management of TB in Children was available in 21 hospitals.

\section{TB suspect management}

The outpatient register was available in 21 hospitals; in 16 hospitals it was noted that TB suspected children $<15$ years old were referred to the DOTS unit for investigation while in the remaining 7 hospitals there were no data on where suspects were referred.

In total 507489 children aged < 15 years were registered in the OPD register and among them 1974 cases (0.4\%) were recognized as TB suspects and registered in the $\mathrm{TB}$ suspect register 
books (Figure 1). The majority of these suspected TB cases $(80.6 \%)$ were aged 6-15 years (Table 1 ). The sex distribution showed a slight predominance of females (58.6\%) compared with males (41.4\%).

Among 1974 TB suspects, 1352 (68.5\%) were registered in the laboratory register books for performing sputum smear examinations. Among these registered TB suspects, 24 (1.8\%) were aged $<5$ years. Sputum smear results were not available in $106 / 1352$ cases $(7.8 \%)$ because the child could not produce sputum for examinations so AFB examinations were available in 1246 suspects registered for smears (Figure 1).

The sputum smear examinations were positive in 114 suspected cases (9.1\%) and negative in 1132 (90.9\%). There were no SS+ cases aged $<5$ years (Table 1). Among these SS+ cases, 98/114 (86.0\%) were registered for TB treatment in the TB register books of the DOTS unit, while 16 cases $(14.0 \%)$ were not registered, resulting in early defaulters. Among the SS- cases, 726/1132 were diagnosed as pulmonary TB based on clinical features (both smear positive and sputum negative), contact history with TB patients and follow-up results by broad-spectrum antibiotic. Only $55 / 726$ cases $(7.6 \%)$ were diagnosed by chest X-ray. Among these cases, $77 / 726(10.6 \%)$ were aged $<5$ years. The majority of patients registered as SS-pulmonary TB ( 408 cases; $56.2 \%$ ) could not induce sputum and were classified as "pulmonary TB sputum not done" and there were 220 SS- pulmonary TB cases with sputum smear examinations done (30.3\%). The remaining 98 cases were SS+

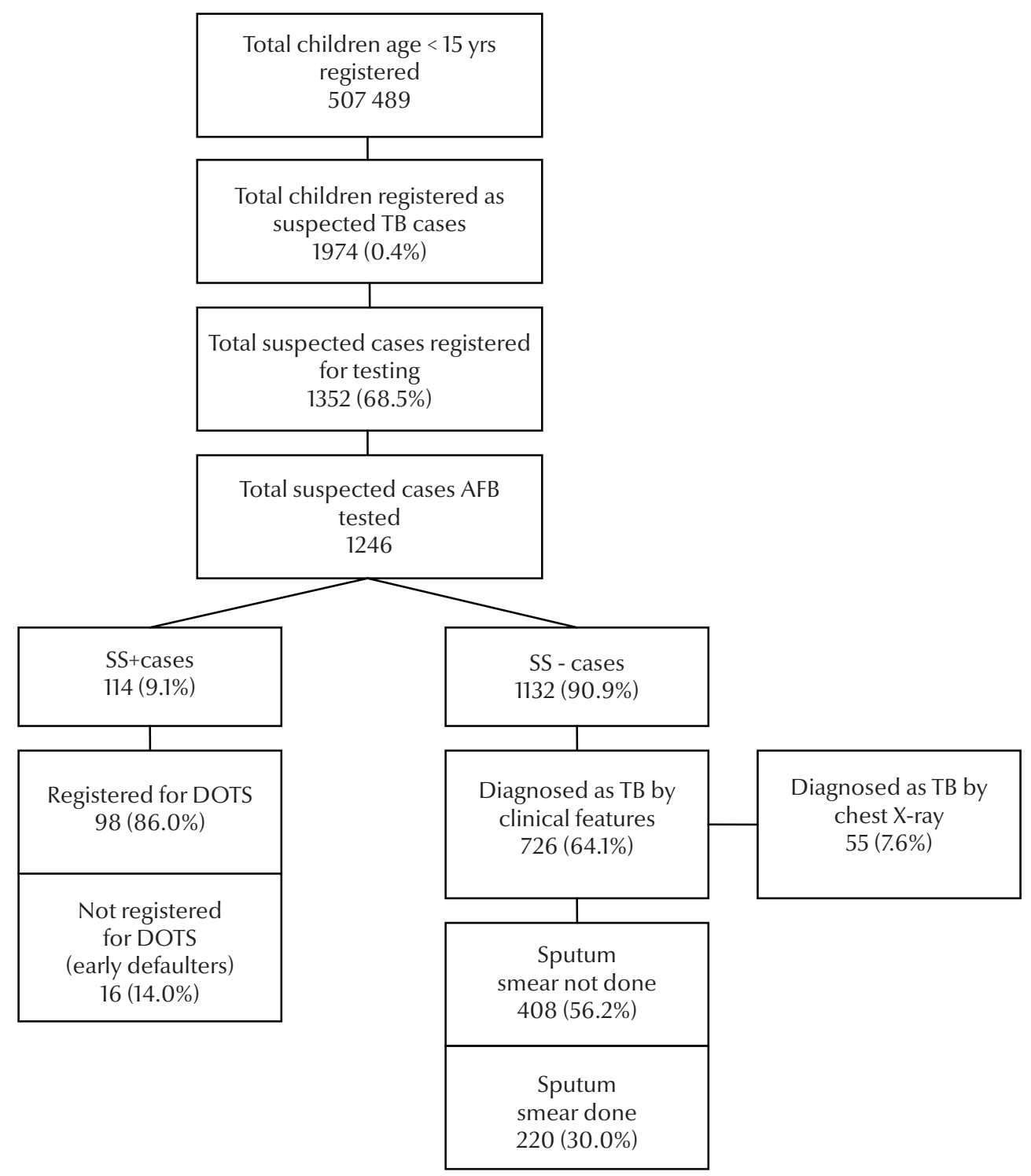

Figure 1 Tuberculosis (TB) suspect management in the surveyed hospitals (AFB = acid fast bacilli, SS $+=$ sputum smear positive, SS- = sputum smear negative) 


\begin{tabular}{|c|c|c|c|c|c|c|c|c|c|}
\hline \multirow[t]{2}{*}{ Variable } & \multirow{2}{*}{$\begin{array}{c}\text { Total } \\
\text { No. }\end{array}$} & \multicolumn{2}{|c|}{ Males } & \multicolumn{2}{|c|}{ Females } & \multicolumn{2}{|c|}{$0-5$ yrs } & \multicolumn{2}{|c|}{ 6-15 yrs } \\
\hline & & No. & $\%$ & No. & $\%$ & No. & $\%$ & No. & $\%$ \\
\hline Registered TB suspects & 1974 & 818 & 41.4 & 1156 & 58.6 & 383 & 19.4 & 1591 & 80.6 \\
\hline Suspects tested for AFB & 1246 & 584 & 46.9 & 662 & 53.1 & 5 & 0.4 & 1241 & 99.6 \\
\hline $\mathrm{AFB}+$ & 114 & 52 & 45.6 & 62 & 54.4 & 0 & 0.0 & 114 & 100.0 \\
\hline AFB- & 1157 & 576 & 49.8 & 581 & 50.2 & 5 & 0.4 & 1152 & 99.6 \\
\hline
\end{tabular}

\section{Diagnosed TB cases}

In total, 971 child TB cases were under treatment during the study, 43 (4.4\%) of whom were aged $<5$ years. The sources of these 971 cases were classified as follows: $94.0 \%$ were considered as new cases, $1.4 \%$ transferred-in cases, $0.6 \%$ relapsed cases, $0.3 \%$ treatment after failure and $3.3 \%$ unknown. The diagnoses were as follows: $10.1 \% \mathrm{SS}+$ pulmonary TB, $22.7 \%$ SS - pulmonary TB, $42.0 \%$ "sputum not done" pulmonary TB, 22.6\% extrapulmonary $\mathrm{TB}$ and $2.7 \%$ unknown diagnosis (Table 2).

Of the extrapulmonary cases, $33 / 219(15.1 \%)$ were aged $<5$ years. For those extrapulmonary TB cases, diagnosis was as follows: lymphadenitis (36.1\%), intestinal TB (32.4\%), pleural effusion (10.0\%), bone TB (8.7\%), TB meningitis (5.9\%), miliary TB (2.7\%), cutaneous TB (0.9\%), unknown (3.3\%).

\section{BCG status among diagnosed TB cases}

Of the paediatric TB cases under treatment, BCG vaccine scar was recorded for 186/971 (19.2\%). In contrast with all other findings, this showed a predominance of males $(111 / 186 ; 59.7 \%)$ than females (75/186; 40.3\%). Among $43 \mathrm{~TB}$ cases aged $<5$ years BCG scar was recorded in the treatment cards in 34 cases $(79.1 \%)$. This rate was higher among TB cases aged $6-15$ years old $(152 / 918 ; 16.6 \%)$. There were no severe types of $\mathrm{TB}$ such as miliary $\mathrm{TB}$ or TB meningitis among BCG vaccinated paediatric TB cases.

\section{TB treatment}

The different hospitals used various treatment combinations of the TB drugs rifampin $(\mathrm{R})$, isoniazid $(\mathrm{H})$, pyrazinamide $(\mathrm{Z})$, ethambutol (E)

\begin{tabular}{lcc}
\hline Table 2 Diagnosed childhood tuberculosis (TB) cases under treatment & \\
\hline Variable & No. & $\%$ \\
Total child cases under treatment & 971 & 100.0 \\
Source of cases & 916 & 94.3 \\
New cases & 14 & 1.4 \\
Transferred-in cases & 6 & 0.6 \\
Relapsed cases & 3 & 0.3 \\
Treatment after failure cases & 32 & 3.3 \\
Unknown status & & \\
Diagnosis & 98 & 10.1 \\
SS+ pulmonary TB & 220 & 22.7 \\
SS- pulmonary TB & 408 & 42.0 \\
Pulmonary TB sputum not done & 219 & 22.6 \\
Extrapulmonary TB & 26 & 2.7 \\
Unknown diagnosis & & \\
\hline
\end{tabular}

SS+ = sputum smear positive; $S S_{-}=$sputum smear negative. and streptomycin (S). The NTP guidelines recommend 2 months RHZ followed by 4 months RH (2RHX/4RH) as the anti-TB treatment regimen for category I TB children; 19 hospitals used this regime, 2 hospitals used $2 \mathrm{RHZE} / 4 \mathrm{RH}$ and 1 used $2 \mathrm{SHZR} / 6 \mathrm{EH}$. The anti- $\mathrm{TB}$ regimen recommended for category II TB children is 2RHZES/1RHZE/5RHE and 22 hospitals used this regime, while 1 hospital did not.

Among the SS+ cases registered for TB treatment, treatment was completed in 84/98 cases at the time of the survey. The sputum conversion rate was $83 / 84$ cases $(98.8 \%)$.

Treatment outcome was also evaluated for 517 paediatric TB cases who were registered 1 year before the study; the treatment completion rate was $86.3 \%$, cured rate was $8.7 \%$ and totally successful treatment completion rate was $95.0 \%$. The transferred-out rate, default rate and death rate were $2.5 \%$ and $1.2 \%$ and $1.4 \%$ respectively.

\section{Contact management}

There were 17 hospitals that registered contacts of TB cases. For the 1039 SS+ pulmonary $\mathrm{TB}$ cases at these hospitals 2697 contacts were registered, 760 (28.2\%) of which were child contacts aged $<15$ years, i.e. $73.1 \%$ of SS + cases had child contacts. The other 6 hospitals did not record the contacts in the register. Diagnostic methods for these child contacts were direct sputum microscopy conducted for 103/760 cases (13.6\%), chest X-ray for 182 
(23.9\%) and tuberculin skin test (TST) for 144 (18.9\%). Among 103 cases who received direct sputum microscopy, 6 (5.8\%) were diagnosed as $\mathrm{TB}$ and 14 $(13.6 \%)$ and $3(2.9 \%)$ were diagnosed as TB by both microscopy and X-ray or TST respectively.

\section{Discussion}

This survey revealed several issues in paediatric TB control in Afghanistan. The key findings were:

- low suspect rate among total outpatient cases $(0.4 \%)$ and very low suspect rate among children aged < 5 years;

- low performance of suspect management (only $68.5 \%$ of suspects received further examinations);

- low utilization of other diagnostic methods (only $7.6 \%$ were diagnosed by chest $X$-ray);

- high early defaulter rate (14.0\%).

- relatively good treatment outcomes (sputum conversion rate of $98.8 \%$ and treatment completion rate of $86.3 \%)$;

- insufficient coverage of child contact management (73.1\%);

- relatively good performance in implementation of isoniazid preventive therapy;

- likely effects of BCG vaccination in preventing the severer forms of $\mathrm{TB}$.

The most important and challenging problem found in this survey was adequate diagnosis of $\mathrm{TB}$ in children, especially in children aged $<5$ years, as has been noted in surveys elsewhere $[3,4]$. The Afghanistan NTP developed the Standard Operational Procedure for Management of Tuberculosis in Children which defines diagnostic procedures of TB in children. In these operational procedures, it is required to use both TST and X-ray in addition to clinical symptoms, especially in children aged < 5 years, because sputum examinations are not available in most cases. However, there was a very low rate of utilization of TST or X-ray for diagnosis in our hospitals. Moreover, no case was diagnosed by combined methods. Thus, the accuracy of diagnosis remained doubtful and, although there were more paediatric TB cases than estimated, the actual burden and incidence of $\mathrm{TB}$ in children are still unclear.

Despite the poor availability of TST in Afghanistan, utilization of chest Xrays for diagnosis was also very limited, even though all hospitals included in this survey had an X-ray unit. This survey did not include an evaluation of the quality of X-ray diagnosis, but there are not only technical, but also infrastructural problems for providing quality X-ray diagnosis in Afghanistan. Thus, for enhancing quality diagnosis of paediatric TB, methods not defined in the standard operational procedures guidelines might be considered [4].

Another important point is the high early defaulter rate before initiating treatment (14.0\%), compared with an acceptable defaulter rate after initiation of treatment of $1.2 \%$. Since there has been no exact data on the early defaulter rate among adult TB cases in Afghanistan and also no definite report on early defaulters among paediatric $\mathrm{TB}$ cases in other countries, it is difficult to exactly assess the significance of this early defaulter rate in the survey. As a report which focused on defaulters, Da Silva et al. in Brazil reported a $24.2 \%$ treatment default rate among paediatric TB cases [9]. In their report, family problems were considered as the important cause of defaulting. For early defaulters before initiating treatment, there have been several reports which include all TB cases, and defaulter rate was close to $15 \%$ in 3 reports and $8 \%$ in the remaining report [10-13]. These reports indicated several reasons for early defaulting which include problems of health services and health systems. Though our survey did not aim to detect reasons for defaulting, similar mechanisms might be suspected. In general, insufficient suspect management is a common problem in the TB control programme in Afghanistan too, and many suspects miss sputum examinations. However, missing cases likely occur when referring suspects from a health facility without diagnostic capacity to TB diagnostic centres in a different location. A total of 507489 children aged $<15$ years were registered in the outpatient department register and among them 1974 cases (0.4\%) were registered as suspected cases. But according to the standard operating procedures for case detection at least $10 \%$ of outpatients should be suspected as TB. Our survey therefore revealed many missing cases within the same hospitals. Thus, it is indicated that poor suspect management has played a crucial role in early defaulting in this survey.

According to the findings of this study the children who were vaccinated by BCG did not develop severe forms of TB such as meningitis or miliary TB, suggesting a long-lasting effect of BCG on prevention of severe forms of $\mathrm{TB}$ as indicated by WHO [14] and by previous reports [15]. There was a significant difference in the percentage of BCG vaccinated cases between cases aged < 5 years and others, although in some cases scars of BCG could fade after a number of years. This might depend on improved performance of the expanded programme on immunization (EPI) in recent years. Thus, it is expected that number of severe forms of TB will decrease continuously if the EPI performance also continues to improve.

We conclude that to enhance quality of paediatric TB control, the Afghanistan NTP needs to develop plans to improve quality of diagnosis of paediatric TB cases including TST and chest X-ray. Also, the country needs to develop a plan to strengthen paediatric TB suspect management and contact management.

Competing interests: None declared. 


\section{References}

1. The Stop TB Strategy. Geneva, World Health Organization, 2006 (WHO/HTM/TB/2006.368).

2. Implementing the WHO Stop TB Strategy: a handbook for national tuberculosis control programs. Geneva, World Health Organization, 2008.

3. Starke JR. Childhood tuberculosis: ending the neglect. International Journal of Tuberculosis and Lung Disease, 2002, 6:373-374.

4. Eamranond P, Jaramillo E. Tuberculosis in children: reassessing the need for improved diagnosis in global control strategies. International Journal of Tuberculosis and Lung Disease, 2001, 5:594-603.

5. Nelson LJ, Wells CD. Global epidemiology of childhood tuberculosis. International Journal of Tuberculosis and Lung Disease, 2004, 8:636-647.

6. Marais BJ et al. The burden of childhood tuberculosis: a public health perspective. International Journal of Tuberculosis and Lung Disease, 2005, 9:1305-1313.

7. Safdar N et al. Diagnosis and outcome of childhood tuberculosis: implementing public health policy in three districts of Pakistan. International Journal of Tuberculosis and Lung Disease, 2010, 14:872-877.

8. Annual report 2010. Kabul, Afghanistan National Tuberculosis Control Program/World Health Organization, 2011.
9. Oliveira VL, da Cunha AJLA, Alves R. Tuberculosis treatment default among Brazilian children. International Journal of Tuberculosis and Lung Disease, 2006, 10:864-869.

10. Buu TN, Lönnroth K, Quy HT. Initial defaulting in the National Tuberculosis Programme in Ho Chi Minh City, Vietnam: a survey of extent, reasons and alternative actions taken following default. International Journal of Tuberculosis and Lung Disease, 2003, 7:735-741.

11. Squire SB et al. "Lost" smear-positive pulmonary tuberculosis cases: where are they and why did we lose them? International Journal of Tuberculosis and Lung Disease, 2005, 9:25-31.

12. Botha $\mathrm{E}$ et al. Initial default from tuberculosis treatment: how often does it happen and what are the reasons? International Journal of Tuberculosis and Lung Disease, 2008, 12:820-823.

13. Botha $\mathrm{E}$ et al. From suspect to patient: tuberculosis diagnosis and treatment initiation in health facilities in South Africa. International Journal of Tuberculosis and Lung Disease, 2008, 12:936-941.

14. World Health Organization. Development of a vaccine effective against avian influenza H5N1 infection in humans. Weekly Epidemiological Record, 2004, 79:25-26.

15. Barreto ML et al. Neonatal BCG protection against tuberculosis lats for 20 years in Brazil. International Journal of Tuberculosis and Lung Disease, 2009, 5:1171-1173. 